\title{
Correction to: Textbook of Assisted Reproduction
}

\author{
Gautam Nand Allahbadia, Baris Ata, Steven R. Lindheim, \\ Bryan J. Woodward, and Bala Bhagavath
}

\section{Correction to: \\ G. N. Allahbadia et al. (eds.), Textbook of Assisted Reproduction, https://doi.org/10.1007/978-981-15-2377-9}

The original version of the book has been revised with the following corrections in the book's front matter.

1. Affiliation of Dr. Baris Ata in the FM has been updated as

Division of Reproductive Endocrinology and Infertility,

Department of Obstetrics and Gynecology,

Koç University School of Medicine,

Istanbul, Turkey.

2. The below corrections are made in the list of contributors section in the front matter of the book.

- Name of Dr. Alteri has been revised to Alessandra Alteri

- Degree of Dr. Amy Barrie has been updated as PhD

- Degree of Christophe Blockeels has been updated as PhD, MD

- Degree of Ivor Cullen has been updated as Ivor Cullen, MD

- Name and degree of Dr. Racheal Cutting, MB, has been changed as Rachel Cutting, MBE

- Dr. Petra De Sutter, Department of Reproductive Medicine, Gent University Hospital, Gent, Belgium should read as Dr. Petra De Sutter, Department of Reproductive Medicine, Ghent University Hospital, Ghent, Belgium.

- Dr. Chloë De Roo, MD, Department of Reproductive Medicine, Gent University Hospital, Ghent, Belgium should read as Dr. Chloë De Roo, MD, Department of Reproductive Medicine, Ghent University Hospital, Ghent, Belgium.

- Dr. Sylvie Lierman, BSc, Department of Reproductive Medicine, Gent University Hospital, Ghent, Belgium should read as Dr. Sylvie Lierman, BSc, Department of Reproductive Medicine, Ghent University Hospital, Ghent, Belgium.

- Dr. Kelly Tilleman, PhD, Department of Reproductive Medicine, Gent University Hospital, Gent, Belgium should read as Dr. Kelly Tilleman, PhD, Department of Reproductive Medicine, Ghent University Hospital, Gent, Belgium.

- Degree of Dr. Sheryl Homa, MD, has been changed as Sheryl Homa, PhD

- Name and degree of Dr. Eleanor Taylor T has been changed as Eleanor Taylor, PhD

3. In Chapter 42, the coauthor Racheal Cutting's name has been changed as Rachel Cutting.

The updated online version of this book can be found at

https://doi.org/10.1007/978-981-15-2377-9

https://doi.org/10.1007/978-981-15-2377-9_42 